\title{
The alpha subunit of RNA polymerase and transcription antitermination
}

\author{
Alan T. Schauer, ${ }^{1}$ Sheau-Wei C. Cheng, ${ }^{1}$ \\ Chuanhai Zheng, ${ }^{1,3}$ Linda St. Pierre, ${ }^{1}{ }^{\text {Diane Alessi }}{ }^{1{ }^{\dagger}}$ \\ Debra L. Hidayetoglu, ${ }^{1 \dagger}$ Nina Costantino, ${ }^{2}$ \\ Donald L. Court ${ }^{2}$ and David I. Friedman ${ }^{1 *}$ \\ ${ }^{1}$ Department of Microbiology and Immunology, The \\ University of Michigan Medical School, Ann Arbor, \\ Michigan 48109 0620, USA. \\ ${ }^{2}$ Laboratory of Chromosome Biology, ABL-Basic \\ Research Program, NCl-Frederick Cancer Research and \\ Development Center, PO Box B, Frederick, Maryland \\ 21702, USA. \\ ${ }^{3}$ Cancer Biology Laboratories, Department of Pathology, \\ College of Veterinary Medicine, Cornell University, \\ Ithaca, New York 14853, USA.
}

\section{Summary}

The $\boldsymbol{N}$ gene product of coliphage $\lambda$, with a number of host proteins (Nus factors), regulates phage gene expression by modifying RNA polymerase to a form that overrides transcription-termination signals. Mutations in host nus genes diminish this N-mediated antitermination. Here, we report the isolation and characterization of the rpoAD305E mutation, a single amino acid change in the carboxy terminal domain (CTD) of the a subunit of RNA polymerase, that enhances $\mathrm{N}$-mediated antitermination. A deletion of the $3^{\prime}$ terminus of $r p o A$, resulting in the expression of an $\alpha$ subunit missing the CTD, also enhances $\mathrm{N}$ mediated antitermination and, similar to rpoAD305E, suppresses the effect of nus mutations. Thus, the NNus complex may be affected through contacts with the CTD of the $\alpha$ subunit of RNA polymerase, as is a group of regulatory proteins that influences initiation of transcription. What distinguishes our findings on the $\mathrm{N}$-Nus complex from those of previous studies with transcription proteins is that all of the regulators characterized in those studies bind DNA and influence transcription initiation; whereas the $\mathrm{N}-\mathrm{Nus}$ complex binds RNA and affects transcription elongation. A screen of some previously identified rpoA

Received 1 April, 1996; revised 29 May, 1996; accepted 7 June, 1996. †Present address: Parke-Davis Pharmaceutical Research, Division of Warner-Lambert Company, Ann Arbor, Michigan 48105, USA.*For correspondence. E-mail davidfri@umich.edu; Tel. (313) 763 3142; Fax (313) 7643562. mutations that influence transcription activators revealed only one other amino acid change, $\mathrm{L} 290 \mathrm{H}$, in the CTD of the $\alpha$ subunit, that influences antitermination. Although our results provide evidence that interactions of the $\alpha$ subunit of RNA polymerase must be considered in forming models of transcription antitermination, they do not provide information as to whether the interactions of $\alpha$ that ultimately influence antitermination occur during initiation or during elongation of transcription.

\section{Introduction}

Programmed regulation of transcription termination is one strategy for control of gene expression that is employed by a wide variety of organisms (Das, 1993). This modulated readthrough of transcription-termination signals, called transcription antitermination, was originally postulated to explain the activation of coliphage $\lambda$ delayed-early genes by the phage-encoded $N$ gene product (Roberts, 1969). Genetic studies of this antitermination process have identified a set of Escherichia coli genes, nus, whose protein products are required for effective $\mathrm{N}$-mediated antitermination (Friedman et al., 1984a). Some of these Nus proteins serve as transcription-elongation factors for $E$. coli (reviewed by Yager and Von Hippel, 1987) and all are essential for host viability (Friedman and Court, 1995). The participation of a large number of proteins in antitermination raises the obvious question of how the members of such a collection of host and viral proteins interact with each other and, importantly, how the complex itself interacts with RNA polymerase (RNP) to create a termination-resistant transcription complex (Das, 1992; 1993; Friedman, 1988; Roberts, 1992; 1993; Greenblatt et al., 1993).

Central to N-mediated modification of RNA polymerase are the nut signals (Rosenberg et al., 1978; Salstrom and Szybalski, 1978a). Located downstream of the early $\lambda$ promoters, $\mathrm{pL}$ and $\mathrm{pR}$, the nut sites direct the assembly of the antitermination complex. Transcripts initiating at $\mathrm{pL}$ and $\mathrm{pR}$ are partially terminated at Rho-dependent terminators tL1 and tR1, respectively (see Fig. 1) (Roberts, 1969; Salstrom and Szybalski, 1978b). The resulting short pL transcript includes the message of the $N$ gene, whose product, N, acts with the host Nus proteins at the NUT RNA signals (Rosenberg et al., 1978; Somasekhar et al., 

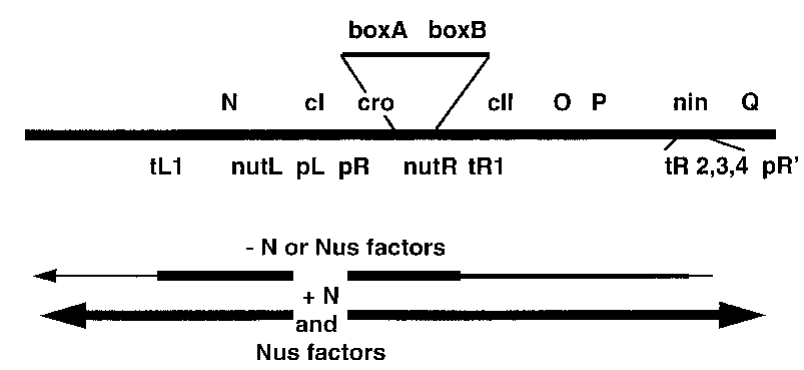

Fig. 1. Schematic genetic map of the early transcribed region of the $\lambda$ genome. The positions of representative genes are indicated above the bold line, with an expansion of the nutR site showing the relative positions of boxA and boxB. The nutL site is positioned downstream of $\mathrm{pL}$ in the opposite orientation to nutR. Below the line are shown the positions of sequences containing signals (promoters, nut sites, and terminators). Lower part of the figure shows the nature of transcription in the absence and presence of effective $\mathrm{N}-\mathrm{Nus}$ complexes.

1982; Lazinski et al., 1989; Salstrom and Szybalski, 1978a,b; Barik et al., 1987; Olson et al., 1982; 1984; Warren and Das, 1984; Zuber et al., 1987; Nodwell and Greenblatt, 1991; Friedman et al., 1990; 1984a) to modify the transcribing RNA polymerase. The nut regions have been divided by sequence homologies, as well as by function, into two components (Friedman and Olson, 1983; Olson et al., 1984; Hasan and Szybalski, 1986; Lazinski et al., 1989). The BOX-A component appears to be the recognition site for the NusB and possibly the S10 (NusE) proteins (Friedman et al., 1990; Nodwell and Greenblatt, 1993; Patterson et al., 1994) and an inhibitory host factor whose existence has been inferred from results of genetic and physiological studies (Patterson et al., 1994). The BOX-B component, a region of hyphenated dyad symmetry that forms a hairpin, has been identified as the recognition site for $\mathrm{N}$ and NusA (Doelling and Franklin, 1989; Lazinski et al., 1989; Das, 1992; Chattopadhyay et al., 1995; Mogridge et al., 1995). (Note that the following convention is being followed in labelling nucleic acid sites: the DNA site will be in lower-case italics and the RNA site will be capitalized, e.g. the DNA will be referred to as 'nut', while the RNA will be referred to as 'NUT'.)

Most of the Nus factors were identified by mutations that influence the effectiveness of the $\mathrm{N}$-mediated antitermination process without affecting host viability. Subsequent in vitro studies confirmed the essential roles of these products in this antitermination process (Das and Wolska, 1984; Horwitz et al., 1987). Two types of mutations were employed in those studies. The first are mutations that cause a failure in $\mathrm{N}$-mediated antitermination at higher temperatures, a phenotype we shall refer to as $\mathrm{Nus}^{-}$( $\underline{\mathrm{N}}$ undersupplied). Two of these mutations, nusA1 at minute 69 and nusB5 at minute 11 on the E. coli chromosome, are located in genes that had not previously been identified and thus were defined by their antitermination defect. Three are in genes that were of known function: $\mathrm{rps} /$ /nusE, encodes ribosomal protein $\mathrm{S} 10$ and is located at minute 72 ; rho/nusD, encodes the Rho transcription-termination protein and is located at minute 90; and $r p o B$, encodes the $\beta$ subunit of RNA polymerase and is located at minute 85 (reviewed in: Friedman et al., 1984a; Das, 1992; Greenblatt et al., 1993; Friedman, 1992). Hosts with any of these nus mutations have a reduced ability to support $\lambda$ growth, solely because of a defect in $\mathrm{N}$-mediated antitermination.

The other type of mutations used to identify host factors involved in $\mathrm{N}$ action are second-site suppressors that were isolated on the basis of restoring $\mathrm{N}$ antitermination activity in the presence of nusA1. Second-site suppressor mutations of this type were identified as rif $^{r}$ mutations in the rpoB gene (Sparkowski and Das, 1992; Jin et al., 1988), the nusB101 mutation (Ward et al., 1983; Court et al., 1995) and the nusG4 mutation in a previously unidentified gene (Downing et al., 1990). In vitro studies provided evidence that NusG is a component of the $\mathrm{N}$-antitermination complex (Li et al., 1992). However, its role in antitermination has not been definitively established, because depleting NusG in the cell does not result in reduced antitermination (Sullivan and Gottesman, 1992). Although other phenotypes associated with mutations in nus genes have been identified (Tsugawa et al., 1988; Ward et al., 1983; Kur et al., 1989; Kuroki et al., 1982; Miyashita et al., 1982; Ward and Gottesman, 1981; Zheng and Friedman, 1994; Court et al., 1995), this discussion will be limited to those mutations that influence $\mathrm{N}$ action by causing or suppressing a Nus ${ }^{-}$phenotype.

The nusB101 and nusG4 mutations also suppress the Nus $^{-}$phenotype imposed by the nusE71 mutation (Ward et al., 1983; Sullivan et al., 1992). Mutations identified in $\lambda$ that exhibit similar suppression of the nusA1 and nusE71 mutations have been located in the nutR-boxA sequence (Friedman et al., 1990) and in the $N$ gene (Schauer et al., 1987; Franklin, 1985). These mutations were initially selected because they fostered $\lambda$ growth in $E$. coli nusA1 mutants, but they subsequently were also shown to foster $\lambda$ growth in E. coli nusE71 mutants (Schauer et al., 1987; Friedman and Olson, 1983). With the exception of nusB101, which was not tested for the obvious reason that it is a nusB mutation, all of these suppressors, bacterial as well as phage, show relatively poor suppression of the Nus $^{-}$phenotype conferred by the nusB5 mutation (Schauer et al., 1987; Ward et al., 1983). It has been suggested that suppressor mutations that alter a component of the $\mathrm{N}$-Nus complex suppress because they enhance (one or more) interactions in the complex, compensating for a suboptimal interaction caused by the primary nus mutation (Schauer and Friedman, 1985; Das, 1992).

We report that mutations in the rpoA gene also suppress defective $\mathrm{N}-\mathrm{Nus}-m e d i a t e d$ transcription antitermination 
caused by nus mutations. These rpoA mutations change amino acids within a small segment of the carboxy terminal domain (CTD) of the $\alpha$ subunit of RNA polymerase, indicating that a distinct molecular surface may contribute to the control of the activity of the $\mathrm{N}-\mathrm{Nus}$ complex.

\section{Results}

Selection of rpoAD305E, a second-site suppressor of nusE71

The rpoAD305E mutation, originally called sneA16 (Friedman, 1988; Schauer, 1985; Schauer and Friedman, 1985), was isolated by selecting for second-site mutations that suppress the Nus ${ }^{-}$phenotype of an E. coli strain carrying the nusE71 mutation. The selection was essentially that devised by Ward et al. (1983). The E. coli strain (K1953) used in the selection carries the nusE71 mutation and has the $g a l$ operon under the control of the $\lambda \mathrm{pL}$ promoter (Fig. 2). Because of intervening transcription terminators, expression of gal genes is entirely dependent on $\mathrm{N}$ mediated transcription antitermination. Even though $\mathrm{N}$ is expressed, the strain is $\mathrm{Gal}^{-}$, because the nusE71 mutation does not support $\mathrm{N}$ action. Thus, suppression of this nusE71 defect would result in a $\mathrm{Gal}^{+}$phenotype. We attempted to direct the mutagenesis to the $72 \mathrm{~min}$ region using P1 transduction for localized mutagenesis (see the Experimental procedures). This region of the $E$. coli chromosome was chosen as a possible location of suppressor mutations, because it is rich in genes encoding ribosomal proteins. We postulated that if one or more ribosomal proteins interacted with $\mathrm{S} 10$ during antitermination, a mutation in one of the genes encoding such a protein might suppress the effect of the nusE71 mutation. The marker selected in the transduction was a Tn10 transposon, zhb-3082::Tn 10, located in this region.

The rpoAD305E mutation, obtained from this selection, was located on the $E$. coli genetic map using standard

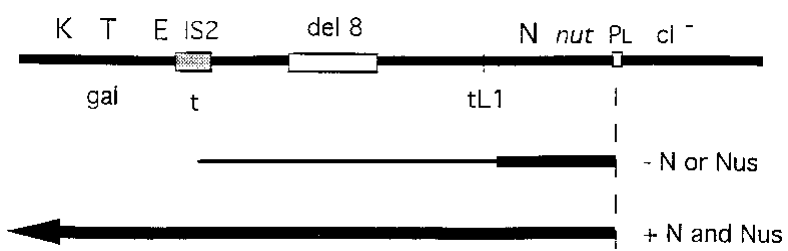

Fig. 2. Fusion for selecting the rpoAD305E mutation and for assessing levels of suppression of nus mutations (after Ward et al. (1983)). The bacterium is a derivative of $E$. coli $\mathrm{K}-12$ in which the bacterial galactose operon $(\mathrm{gal})$ is fused to the $\mathrm{pL}$ promoter of a defective $\lambda$ prophage. The essential components of this abbreviated prophage are: a cl mutation eliminating repressor, the pL promoter, the nutL signal, the $N$ gene, and transcription terminators, including a strong termination signal in an IS 2 positioned immediately $5^{\prime}$ of the structural genes of the gal operon. In a nus ${ }^{-}$derivative, $\mathrm{N}$-modified transcription antitermination is not functional and therefore there is no $\mathrm{gal}_{\text {expression }}\left(\mathrm{Gal}^{-}\right)$. Bacteria with second-site mutations that suppress the nusE71 mutation were selected as $\mathrm{Gal}^{+}$mutants. genetic techniques (Miller, 1972; Sternberg and Maurer, 1991). These manipulations located the $r p o A D 305 E$ mutation, as expected, in the 72 min region of the $E$. coli chromosome, and finer mapping studies suggested that the mutation is in or closely linked to the $r p o A$ gene, which encodes the $\alpha$ subunit of RNA polymerase.

\section{Complementation analysis and marker rescue}

The dominance of the rpoAD305E mutation was characterized using a strain with the rpoAD305E allele on the chromosome. The effectiveness of $\mathrm{N}$ action could be assessed because the bacterium carries the $\mathrm{pL}-\mathrm{gal}$ fusion described above and also in Fig. 2. The bacterium, E. coli K6325, carries, in addition to the fusion, the nusE71 mutation that normally blocks $\mathrm{N}$ action, but because K6325 also carries the rpoAD305E mutation, this blockage of $\mathrm{N}$ action is suppressed. The gal operon can be expressed allowing K6325 to metabolize galactose and thus to form red colonies on a MacConkey-galactose plate at $40^{\circ} \mathrm{C}$. A derivative of $\mathrm{K} 6325$ containing pNO2530 (a plasmid with the wild-type $r p o A$ and $r p / Q$ genes downstream of plac) (Bedwell and Nomura, 1986) forms pink colonies, reflecting a reduction in gal operon expression and thus a reduced suppressor phenotype. Note that under these conditions K1953, the starting nusE71 derivative, forms white colonies (low gal-operon expression) and K1947, the us $^{+}$derivative, forms red colonies (high galoperon expression). Thus, by this assay, $r p o A^{+}$expressed from the pNO2530 plasmid is only partially dominant to the single chromosomal copy of the rpoAD305E allele.

A plasmid with the rpoAD305E allele was obtained from K6325 carrying pNO2530 by identifying rare red colonies on MacConkey-galactose plates containing ampicillin, at $40^{\circ} \mathrm{C}$. Presumably these red-colony formers became homozygous for rpoAD305E as a result of recombination between the chromosomal and plasmid rpoA alleles and subsequent segregation. The details of the screen for the recombinants and the tests confirming the exchange are described in the Experimental procedures. When this new rpoAD305E-containing plasmid, isolated from these red colonies and named pNO2530*, is transformed into the rpo $A^{+}$strain $\mathrm{K} 1953$, the nusE71 defect is suppressed (there is effective gal operon expression as evidenced by formation of red colonies), indicating the trans-dominant nature of the suppressor rpoAD305E mutation in multicopy.

\section{Locating the rpoAD305E mutation to the rpoA gene}

The rpoA insert in pNO2530 is located immediately downstream of the lac promoter (plac). To determine whether rpoAD305E was an allele of $r p o A$, we subcloned DNA fragments from pNO2530 and pNO2530* and placed 

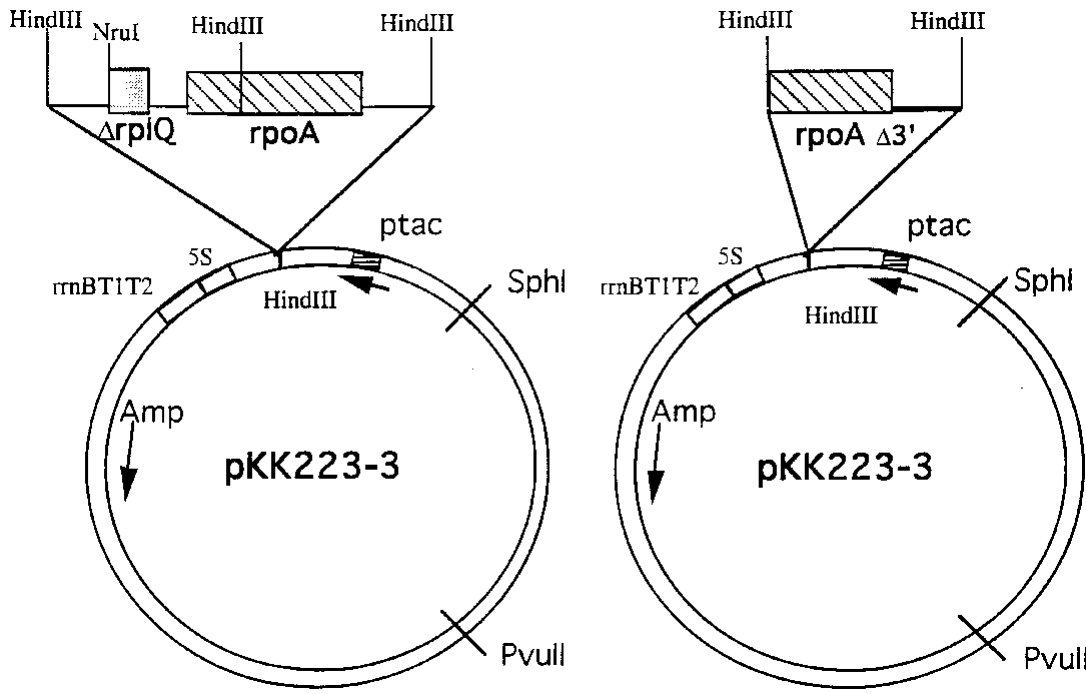

Fig. 3. Derivatives of pKK223-3 (Brosius and Holy, 1984) with cloned rpoA genes. The circles show the cloning vector, and the diagrams above show the nature of the cloned fragment in each construct. $r$ rnBT1T2 are terminators from the $\mathrm{rrnB}$ operon. The position of the $a m p^{r}$ gene is indicated. The cloned $r p o A$ genes are oriented so that they are expressed from the ptac promoter. On the left is shown the extent of the fragment cloned in both pKKrpoA and pKKrpoA*, and on the right is shown the extent of the fragment cloned in pKKrpoA $\Delta 3^{\prime}$. The region of pKK223-3 between the Sphl and Pvull sites was deleted in all of these plasmids. them in the appropriate orientation for expression, downstream of the tac promoter (ptac) in a derivative of plasmid pKK223-3 (de Boer, 1984), as shown diagrammatically in Fig. 3. The resulting plasmids were tested for suppression of the nusE71 mutation. Plasmid pKKrpoA*, which includes the complete rpoA gene and the $5^{\prime}$ two-thirds of $r p / Q$ from pNO2530*, suppresses the nusE71 mutation, whereas the same region from pNO2530 did not. Another plasmid, which includes only the $3^{\prime}$ end of $r p o A$ as well as the $5^{\prime}$ two-thirds of $r p / Q$ from pNO2530* (our unpublished results), fails to suppress the nusE71 mutation. Thus, we conclude that rpoAD305E is indeed an allele of $r p o A$.

\section{Sequencing the rpoAD305E mutation}

Comparison of the DNA sequences of the rpoA genes in pNO2530 and pNO2530* revealed a single nucleotide difference. The former has GAC at codon position 305 as does the published sequence (Meek and Hayward, 1994), while the latter has GAA at that codon position. The derived amino acid sequence for the mutant $\alpha$ subunit has a glutamic acid at position 305 instead of aspartic acid encoded in the wild-type $\alpha$ subunit at that position; we have sequenced the entire fragment that expresses suppressor activity and find this to be the only change from the wildtype sequence. Additionally, sequencing of the mutant chromosomal allele reveals the same change. Therefore, we conclude that the change from an aspartic to a glutamic acid at amino acid position 305 is responsible for the rpoAD305E Nus-suppressor phenotype.

\section{Suppression of other nus mutations}

To characterize the range of suppression by the rpoAD305E mutation, we assessed the effect of rpoAD305E on the Nus $^{-}$phenotypes imposed by mutations in other nus genes. Derivatives of strain K37, each carrying the
rpoAD305E mutation in addition to one of the nus mutations, were tested for their ability to support $\lambda$ growth at high temperatures using efficiency of plating (EOP) as the assay for $\lambda$ growth (Table 1 ).

Results of this assay show that the rpoAD305E mutation suppresses the $\mathrm{Nus}^{-}$phenotypes imposed by all three nus mutations. In this and other assays testing Nus activity, different temperatures were used in assessing the Nus ${ }^{-}$phenotype: $40^{\circ} \mathrm{C}$ for those with nusB5 or nusE71 mutations, and $42^{\circ} \mathrm{C}$ for those with the nusA1 mutation (Friedman et al., 1984a). The two temperatures were used because the nusA1 mutation is not restrictive for $\mathrm{N}$ action at temperatures under $42^{\circ} \mathrm{C}$ and the nusB5 and nusE71 mutations are not suppressed efficiently by rpoAD305E at $42^{\circ} \mathrm{C}$. Under these specific conditions, derivatives of $\mathrm{K} 37\left(r p o A^{+}\right)$carrying the respective nus mutations fail to support $\lambda$ growth. The EOP in each case was $<10^{-5}$. The presence of rpoAD305E in any

Table 1. Suppression of nus mutations by rpoAD305E, as measured by EOP of $\lambda$.

\begin{tabular}{lllrl}
\hline Strain & $\begin{array}{l}\text { Temperature } \\
\left({ }^{\circ} \mathrm{C}\right)\end{array}$ & Relevant genotype & EOP $^{\mathrm{a}}$ & $\begin{array}{l}\text { Plaque } \\
\text { size }\end{array}$ \\
\hline K4069 & 40 & rpoAD305E & 0.7 & Large \\
K556 & 40 & nusE71 & $<10^{-5}$ & \\
K8248 & 40 & nusE71 rpoAD305E & 0.7 & Small \\
K95 & 42 & nusA1 & $<10^{-5}$ & \\
K4047 & 42 & nusA1 rpoAD305E & 0.7 & Tiny \\
K450 & 40 & nusB5 & $<10^{-5}$ & \\
K4070 & 40 & nusB5 rpoAD305E & 0.7 & Very tiny \\
\hline
\end{tabular}

a. EOP is the efficiency of plating. This number is derived from phage titres obtained at the indicated temperatures. EOP is the ratio of the titre on a lawn of the strain with the mutant genotype divided by the titre on a lawn of the parent $E$. coli 'wild-type' strain at the locus being tested. $\lambda$ cl60 was used in this experiment. 
Table 2. Suppression of nus mutations by rpoAD305E as measured from a pL-nut-t-gal fusion in the presence of $\mathrm{N}^{\mathrm{a}}$.

\begin{tabular}{llrl}
\hline & & \multicolumn{2}{c}{ Percent Readthrough } \\
\cline { 3 - 4 } nus allele in strain & Temperature $\left({ }^{\circ} \mathrm{C}\right)$ & $r p o A^{+}$ & rpoAD305E \\
\hline nus $^{+}$ & 40 & 100 & 100 \\
nusA1 & 42 & 13 & 104 \\
nusE71 & 40 & 10 & 48 \\
nusB5 & 40 & 7 & 27 \\
\hline
\end{tabular}

a. See Fig. 2 for details on the $\mathrm{pL}-g a /$ construct.

b. Percent readthrough equals (GalK level expressed from the fusion in the mutant strain divided by the GalK expressed from the fusion in the parent strain (wild type for relevant markers)) $\times 100$. GalK levels were measured as indicated in the Experimental procedures.

one of these nus-mutant strains results in an increase of the EOP to nearly 1.

We next employed a more direct assay to assess the degree of suppression by the rpoAD305E mutation. Suppression was quantitatively assessed using bacterial derivatives with the previously described $\mathrm{pL}-$ gal fusion (Fig. 2). As shown in Table 2, hosts carrying any one of the three nus mutations (nusA1, nusB5, or nusE71) express galK levels that are $\sim 10 \%$ of that observed in the K1947 nus $^{+}$control. In the double rpoAD305E nus mutants, galK expression was significantly higher, varying from $30-100 \%$ of that observed in the nus ${ }^{+}$control. Although there were differences in the level of suppression, the essential point is that the results of this test, similiar to those from the phage plating, show that rpoAD305E suppresses the Nus ${ }^{-}$phenotype of the three nus mutations.

\section{Suppression by a truncated rpoA gene}

In vitro studies on the action of transcription activators have shown that RNA polymerase with an $\alpha$ subunit deleted at the carboxy terminus duplicates the effects of point mutations that change specific amino acids in the carboxy terminus of $\alpha$ (Ishihama, 1992). To determine if there was a similar effect on suppression of nus mutations, we examined whether the truncated $\alpha$ subunit, expressed from an rpo $A$ gene deleted for its $3^{\prime}$ domain, affects the Nus $^{-}$phenotype of $E$. coli derivatives with nus mutations. E. coli strains haploid for an $r p o A 3^{\prime}$ deletion are not viable, but plasmids expressing the truncated $r p o A$ can be maintained in strains that are wild type for rpoA (Hayward et al., 1991). Based on these findings and our observation that plasmids expressing the rpoAD305E allele are trans-dominant, we postulated that a $3^{\prime}$ deletion of $r p o A$ might suppress the Nus ${ }^{-}$phenotype. This hypothesis was tested using a plasmid expressing the $3^{\prime}$-deleted rpoA gene. Three plasmids, pKKrpoA, pKKrpo $A^{*}$, and pKKrpoA $\Delta 3^{\prime}$ (see Fig. 3), were tested in parallel for suppression of nus mutations.
Sequence analysis predicts that $\mathrm{pKKrpoA} \Delta 3^{\prime}$ should express an $\alpha$ subunit that is truncated at amino acid 229 where an additional 15 amino acids encoded by the vector sequence are added. Western blot analysis, using an anti- $\alpha$ monoclonal antibody, identified a protein corresponding to the size predicted for the truncated polypeptide in bacteria carrying pKKrpoA $\Delta 3^{\prime}$. This protein is not seen in control bacteria that do not contain the plasmid (data not shown).

The suppressor activity of the plasmid-based rpo $A$ alleles was examined by assessing the effects on $\lambda$ growth as measured by EOP. As shown in Table 3, the $r p o A \Delta 3^{\prime}$ allele, like the rpoAD305E allele, suppresses the Nus ${ }^{-}$phenotype of both the nusE71 and nusA1 mutations. In contrast, when the wild type rpoA allele is expressed from a plasmid constructed from the same vector, neither nus mutation is suppressed. Although these results clearly demonstrate that the two mutant rpo $A$ alleles suppress the Nus ${ }^{-}$phenotype, interpretation of the quantitative results is complicated by the necessity of having a wild-type rpoA allele for viability. Therefore, the finding that the increase in EOP effected by either the plasmid-based $r p o A D 305 E$ or $r p o A \Delta 3^{\prime}$ allele is lower in the nusA1 mutant than in the nusE71 mutant could suggest a difference in suppression, but also could result from complications owing to the presence of the wild-type rpoA allele. The pattern of suppression of the nus $B 5$ mutation is qualitatively different. By this test the $r p o A \Delta 3^{\prime}$ mutation, similar to the wild-type allele, fails to suppress the nusB5 mutation, while the rpoAD305E allele does so weakly. We emphasize the essential finding from these experiments that the $r p o A \Delta 3^{\prime}$ allele, like the rpoAD305E allele, suppresses the Nus ${ }^{-}$phenotype of some nus mutations, while pointing out the difficulty in assessing the significance of the quantitative data because of the possibility of interference with suppression by the wild-type rpoA allele.

Table 3. Suppression of nus mutations by plasmid-based rpoA mutations as measured by EOP of $\lambda$.

\begin{tabular}{|c|c|c|c|c|}
\hline Strain & $\begin{array}{l}\text { Temperature } \\
\left({ }^{\circ} \mathrm{C}\right)\end{array}$ & $\begin{array}{l}\text { Relevant } \\
\text { chromosomal } \\
\text { genotype }\end{array}$ & $\begin{array}{l}\text { rpoA allele } \\
\text { on plasmid }\end{array}$ & $\begin{array}{l}\text { EOP of } \\
\lambda^{a}\end{array}$ \\
\hline K95 & 42 & nusA1 & Wild type & $<10^{-5}$ \\
\hline K7565 & 42 & nusA1 & rроAD305E & 0.08 \\
\hline K7625 & 42 & nusA1 & $r p o A \Delta 3^{\prime}$ & 0.02 \\
\hline K450 & 40 & nusB5 & Wild type & $<10^{-5}$ \\
\hline K7568 & 40 & nusB5 & rpoAD305E & 0.05 \\
\hline K7626 & 40 & nusB5 & $r p o A \Delta 3^{\prime}$ & $<10^{-5}$ \\
\hline K556 & 40 & nusE71 & Wild type & $<10^{-5}$ \\
\hline K7571 & 40 & nusE71 & rpoAD305E & 0.8 \\
\hline K7627 & 40 & nusE71 & $r p o A \Delta 3^{\prime}$ & 0.8 \\
\hline
\end{tabular}

a. For details of EOP see Table 1. $\lambda$ cl60 was used in this experiment. 


\section{Effect on transcription initiation and termination}

Studies presented in the previous sections show that $r p o A$ mutations can suppress the effect of mutations in three $E$. coli genes whose products influence $\mathrm{N}$-mediated transcription antitermination. There are two ways to explain this suppression by an rpoA mutation, either by an increase in transcription initiation or by a decrease in transcription termination. Therefore, we assessed the effect of the rpoAD305E mutation on transcription initiation and termination in the absence of $\mathrm{N}$. Beta-galactosidase levels were compared between congenic rpo $A^{+}$and rpoAD305E strains carrying a $\mathrm{pL}-\mathrm{N}-\mathrm{lac} Z$ protein fusion in a defective prophage. There was essentially no difference between the two strains with regard to promoter strength or $\mathrm{N}$ expression, because each expressed $\sim 2000$ units of the $\beta$-galactosidase fused to $\mathrm{N}$. Termination was assessed using three pKL600 derivatives that test the tR2 Rhoindependent or tR1 and tR3 Rho-dependent terminators of phage $\lambda$ (Cheng et al., 1991; 1995; Patterson et al., 1994). Because the transcription terminators are placed upstream of the galK gene, expression of galK provides a measure of termination. We found that the rpoAD305E mutation did not have any significant effect on these terminators (data not shown).

\section{Effect of other rpoA alleles}

We employed a $\lambda$ variant carrying the cro62 mutation to screen other mutations in the carboxy terminus of $r p o A$ for this suppressor phenotype. The cro62 mutation results from a deletion of a single base pair (bp) in the 3 ' terminus of the $\lambda$ cro gene (Olson et al., 1982) that causes a shift in the cro reading frame, resulting in translation extending four nucleotides downstream of the usual UAA termination codon to a UAA codon in the new reading frame. This extension of translation moves the terminating ribosomes closer to the $5^{\prime}$ junction of NUT-R (three nucleotides away instead of seven nucleotides away) and causes a failure in $\mathrm{N}$-mediated antitermination (Olson et al., 1982). Presumably, the shift downstream of the terminating ribosomes interferes with the assembly of the antitermination complex at NUT-R (Olson et al., 1984). This defect in antitermination results in the failure of $\lambda$ cro6 2 to grow in $\mathrm{K} 37$ which is wild type for nus alleles; however, $\lambda$ cro62 grows in $\mathrm{K} 4069$, which is a $\mathrm{K} 37$ derivative carrying the rpoAD305E mutation. $\lambda$ cro62 exhibits a four-log-greater EOP on a lawn formed from K4069 than from a lawn formed from K37 and also shows a similar high EOP on a lawn formed from a K37 derivative carrying a plasmid with the $\operatorname{rpo} A \Delta 3^{\prime}$ allele.

We exploited our observation that the rpoAD305E mutation converts $E$. coli from being non-permissive to being permissive for $\lambda$ cro62 growth, to screen other
Table 4. Effect of rpoA alleles on $\lambda$ cro6 2 growth.

\begin{tabular}{llll}
\hline & & \multicolumn{2}{c}{ Phage tested $^{\mathrm{b}}$} \\
\cline { 3 - 4 } Strain $^{\mathrm{a}}$ & Change in $\alpha$ subunit & $\lambda$ & $\lambda$ cro62 $^{2}$ \\
\hline C1 & None & + & - \\
C4540 & L290H & + & + \\
C4618 & T323S & + & - \\
C4622 & P323L & + & - \\
C4624 & P322S & + & - \\
C4630 & K271E & + & - \\
C4679 & A272T & + & - \\
C4680 & E215K & + & - \\
DC721 & D305E & + & + \\
\hline
\end{tabular}

a. All strains, with one exception, are derivatives of the $r p o A^{+} E$. coli C strain $\mathrm{C} 1$.

b. Phage growth was assessed by a spot test. A lawn of the indicated bacterium was poured onto a Luria-Bertani (LB) plate. A dilution of $\lambda$ sufficient to give single plaques was spotted onto the plate with the seeded lawn. Plates were incubated at $37^{\circ} \mathrm{C}$. +, phage growth; no phage growth. $\lambda$ was $\lambda$ cl857 and $\lambda$ cro6 2 was $\lambda$ cl857 cro62.

rpoA mutations for this suppressor phenotype. A number of rpoA mutations constructed in E. coli C (Ayers et al., 1994) were tested for their ability to enhance antitermination by examining $\lambda$ cro6 2 growth (Table 4). Two control experiments confirmed that we could use this set of otherwise isogenic mutants for this screen. First, $\lambda$ cro62 fails to form plaques on a lawn formed from the parental $E$. coli $C$ strain containing the wild-type rpoA and, second, $\lambda$ cro62 forms plaques on a derivative of this $E$. coli $C$ that carries the rpoAD305E mutation.

Table 4 lists the seven rpoA E. coli $\mathrm{C}$ derivatives tested, and specifies the amino acid change in the encoded $\alpha$ subunit of each strain. This test identified only one other strain, C4540, which had an rpoA mutation that suppresses the antitermination defect. The rpoA mutation in this strain results in a Leu to His change at amino acid position 290.

\section{Discussion}

The $\alpha$ subunit of $E$. coli RNA polymerase has been identified as the probable site for interaction of a number of transcription factors (Ishihama, 1992; Russo and Silhavy, 1992; Ebright and Busby, 1995; Giladi et al., 1992). Mutations influencing the action of such transcription factors are usually found in non-overlapping clusters in the $3^{\prime}$ region of the rpoA gene. Proteolytic treatment of the 329-amino-acid $\alpha$ subunit revealed that the carboxy terminal 85 amino acids form a domain (CTD) that dimerizes and binds to DNA (Blatter et al., 1994). The CTD includes the amino acids changed by the mutations that interfere with the action of transcription activators. Clusters of mutations are located at the following amino acid positions: (i) 265-270, influencing the action of the cAMP-binding protein at the lac P1 promoter (Zou et al., 1992); (ii) 289-290, influencing the Ogr protein of phage P2 
(Ayers et al., 1994; Sunshine and Sauer, 1975); (iii) 311317 , influencing the action of Fnr (an activator of anaerobically expressed genes) (Lombardo et al., 1991); and (iv) 322 or 323 , influencing the action of OmpR and EnvZ (which are regulators of porin expression) (Slauch et al., 1991).

We have identified an $r p o A$ mutation, rpoAD305E, that changes amino acid 305 in the CTD of $\alpha$. This altered $\alpha$ subunit suppresses a variety of mutations, including those in nus genes, that reduce the effectiveness of the $\mathrm{N}$-mediated transcription antitermination system of phage $\lambda$. A screen of seven other rpoA mutations that alter the $\alpha$ CTD and affect transcription-initiation factors (Ayers et al., 1994) identified one additional mutation that exhibits suppression of a defect in $\mathrm{N}$-mediated antitermination. This mutation, rpoA109, changes amino acid 290 of the $\alpha$ subunit and was originally identified because it interferes with the action of the phage-encoded Ogr transcription-activation protein (Sunshine and Sauer, 1975). Those changes in the CTD of $\alpha$ that had no effect on $\mathrm{N}$-mediated antitermination altered amino acids are at positions $215,271,272,322$, and 323 . These mutations are all thought to affect transcription initiation, while the rpoAD305E mutation influences transcription elongation. Moreover, selections that yielded $r p o A$ mutations that affect the actions of other transcription factors have not yielded, to our knowledge, any mutations in codon 305 . Thus, amino acid position 305 appears to have specificity, in this case, for an interaction influencing transcription elongation. Preliminary studies suggest that rpoAD305E, unlike rpoA109 $(\mathrm{L290H})$, does not affect P2 Ogr function (G. Christie, personal communication). Thus, there appears to be overlap, but not identity, of amino acid patches used by the Ogr initiation activator of P2 and the $\mathrm{N}$ antitermination system of $\lambda$.

RNA polymerase reconstituted with an $\alpha$ subunit truncated in its CTD also fails to interact with, and is not stimulated by, activator proteins (Ishihama, 1992). This led to the idea that the point mutations cause changes in the $\alpha$ subunit that block interaction with the activators. To determine if something similar is occurring with rpoAD305E, we examined the effect of a 3 '-truncated $r p o A$ gene on $\mathrm{N}$ mediated antitermination and found that the truncated gene product, like the product of the rpoAD305E allele, suppresses the defect in antitermination caused by nus mutations. These observations raise questions regarding the nature of the interaction influenced by $r p o A D 305 E$. If the results of only the experiments with rpoAD305E were to be considered, a simple explanation for our observations would be that the rpoAD $305 E$ mutation enhances the interaction of one, or more, of the components of the $\mathrm{N}-$ Nus complex with RNA polymerase. Accordingly, this enhanced interaction could compensate for an impaired interaction of another component. The observation that a variant $\alpha$ subunit missing its carboxy terminus also suppresses some Nus ${ }^{-}$phenotypes calls into question enhanced interactions of the $\alpha$ CTD as the cause for suppression by the rpoAD305E mutation. Because the truncated $\alpha$ subunit is missing amino acids that include amino acid 305, suppression cannot be mediated by facilitation of an interaction with amino acids at and near 305 in the carboxy terminus, but, instead, it probably results from a failure to interact with amino acids in this region. This means that rpoAD305E is not sui generis, but, like the other rpoA mutations, is affecting regulatory activity by blocking an interaction with the $\alpha$ subunit. We suggest that antitermination is restored for one of two reasons: either rpoAD305E and $r p o A \Delta 3^{\prime}$ reduce transcription termination or they enhance antitermination. Our experiments with tester systems designed to measure terminator activity appear to rule out the first explanation, because the rpoAD305E mutation has no effect on several $\lambda$ transcription terminators in the absence of $\mathrm{N}$.

We therefore favour the latter explanation, namely that the rpoA mutations stimulate antitermination. This stimulation is unlikely to be caused by overexpression of $\mathrm{N}$ or any of the Nus factors. First, overexpression of N, NusA, NusE, or NusG fails to duplicate the suppressive effects observed with the rpoAD305E mutation (our unpublished results). Second, the rpoAD305E mutation partially suppresses a nusB null mutation for $\lambda$ growth (M. Neeley, D. Court, and D. Friedman, unpublished), showing that NusB is not necessary for the suppression activity of rpoAD305E.

Models explaining how mutations in the $\alpha$ subunit enhance impaired $\mathrm{N}$-mediated transcription elongation would necessarily depend on interactions of $\alpha$ that might occur either at initiation or during elongation of transcription. The former would involve DNA and/or proteins at the promoter in a manner similar to interactions previously described for transcription activators, while the latter would involve interactions downstream of the promoter with the RNA, DNA, and/or a protein(s) composing the antitermination complex. Regardless of the site of the interaction, under conditions of impaired $\mathrm{N}$ action, the final signal to RNA polymerase must result in a failure in $\mathrm{N}$-mediated antitermination that can be relieved by mutations in rpoA. Although we have shown that transcription levels from the $\lambda \mathrm{pL}$ promoter are not affected by the rpoAD305E mutation, this does not rule out the possibility that $\alpha$ activity at the $\mathrm{pL}$ promoter affects transcription antitermination, but in an indirect manner.

As opposed to action at the promoter with a subsequent effect on elongation, $\alpha$ could affect the elongation process per se. For example, an interaction between $\alpha$ and the DNA, similar to that observed at the rrn promoter (Ross et al., 1993) but in this case during elongation, might render polymerase less susceptible to modification by $\mathrm{N}$ 
and Nus factors. Alternatively, an interaction between $\alpha$ and the NUT RNA might hinder formation of the antitermination complex directly, either by interfering with complex formation or by facilitating action of an inhibitor of $\mathrm{N}$ mediated antitermination-complex formation. Liu and Hannah (1995) have shown that, in vitro, the $\alpha$ CTD interacts with the nascent RNA during transcription and this interaction is not observed in the presence of NusA. We have proposed an inhibitor to explain the results of our genetic and physiological studies (Patterson et al., 1994), and an inhibitor was also suggested to explain NusB-independence for processive $\mathrm{N}$-mediated antitermination in vitro with purified protein components (DeVito and Das, 1994). The inhibitor could conceivably prevent antitermination, in part, by interacting with the $\alpha$ subunit of RNA polymerase. According to this model, the suppression observed with rpoAD305E and rpoA $\triangle 3^{\prime}$ mutations (and presumably rpoAL29OH) results from a reduction in the interaction between $\alpha$ and the inhibitor. This loss of inhibitor action, in turn, would permit a more unencumbered assembly of the $\mathrm{N}$ antitermination complex. Under conditions where all components are functioning effectively, the action of the inhibitor would be effectively blocked. However, under conditions less optimal for formation of antitermination complexes (e.g., in the presence of nus mutations), the presence of the inhibitor would interfere with complex formation, leading to a failure in antitermination. Thus, loss of the inhibitor activity would allow for effective complex formation under the suboptimal conditions and result in effective antitermination.

We are unable to propose a definitive model to explain how the rpoAD305E and rpoA $\triangle 3^{\prime}$ mutations suppress the inhibitory effect on $\lambda$ growth caused by the cro62 frameshift mutation, i.e., why $\lambda$ cro6 2 fails to grow in a nus ${ }^{+}$host, $\mathrm{K} 37$, but grows in a derivative of $\mathrm{K} 37$ that carries copies of either the rpoAD305E or rpoA $\triangle 3^{\prime}$ alleles. However, we offer the following hypothesis to explain this observation. The cro62 frameshift results in an incursion of translating ribosomes into the NUT region (Olson et al., 1984) that appears to compete with the efficient entry of $\mathrm{N}$ and/or Nus factors to the NUT site. We suspect that the enhancement of $\mathrm{N}$ action mediated by the $\alpha$ mutations tilts this competition in favour of $\mathrm{N}$ and thus allows growth of $\lambda$ cro62.

In vitro studies by Liu et al. (1996) found that RNA polymerase containing $\alpha$ subunits missing the carboxy terminal domain can be modified by $\mathrm{N}$ and Nus factors into effective antitermination complexes. This indicates that the carboxy terminus of $\alpha$ is not required to assemble the antitermination complex and is consistent with the arguments we have advanced regarding the requirement for the carboxy terminal domain of the $\alpha$ subunit and the putative inhibitory factor.

A role for an inhibitor of transcription elongation has been described in humans. A 213-amino-acid protein encoded by the VHL tumour-suppressor gene has been proposed to modulate transcription by inhibiting action of the SIII transcription-elongation factor (Latif et al., 1993; Duan et al., 1995). Interestingly, it has been pointed out that portions of the p15 subunit of SIII share sequence similarity with the E. coli NusB and Rho transcriptionelongation proteins (Garrett et al., 1994).

In summary, we have presented evidence showing that an interaction that promotes transcription elongation appears to be regulated through interactions with the $\alpha$ subunit of RNA polymerase. As many other studies have identified a role for the $\alpha$ subunit in initiation of transcription, our studies identify an expanded role for this subunit in the transcription-elongation process.

\section{Experimental procedures}

\section{Bacteria}

Relevant genotypes and sources of bacteria used in these studies are listed in Table 5 .

\section{Media}

The media used in these experiments have been described previously (Miller and Friedman, 1980).

\section{Plasmids}

pNO2530, pNO2341, pNO2685, and pNO2695 were supplied by M. Nomura (Cerretti et al., 1983). pNO2530* was obtained by recombining the rpoAD $305 E$ mutation from the chromosome with pNO2530. pKKrpoA (Fig. 3) was constructed by isolating a $1318 \mathrm{bp} \mathrm{Hindlll-Nrul} \mathrm{fragment,} \mathrm{which} \mathrm{contained}$ all of $r p o A$ and a $5^{\prime}$ portion of the adjacent $r p / Q$ gene from pNO2530, and ligating it into the Hindlll site of pKK223-3 (Brosius and Holy, 1984). The resulting plasmid was deleted of 1503 nucleotides of pKK223-3 located between the Sphl and Pvull sites. The identical procedure was followed to construct pKKrpoA*, except that pNO2530* was used as the donor of the Hindlll-Nrul fragment. pKKrpoA $\Delta 3^{\prime}$ was constructed by cloning the $711 \mathrm{bp}$ Hindlll fragment from pNO2530, containing a truncated rpoA gene deleted of its 3 '-terminal 300 nucleotides, into the Hindlll site of pKK2233 (also deleted for the 1503 nucleotides between the Sphl and Pvull sites). pKL600, supplied by K. McKenney, is a terminator-tester plasmid that has a polycloning site between plac and a galK reporter gene (McKenney et al., 1981). pKLtR2 and pKLtR3 are derivatives of pKL600 that have the tR2 (Rho-independent) or tR3 (Rho-dependent) terminators, respectively, of $\lambda$ cloned in the proper orientation in the polycloning site (Cheng et al., 1991; 1995).

\section{Phage and source}

$\lambda c l 60$ and $\lambda$ cl857 were obtained from the $\mathrm{NIH}$ collection; $\lambda c l 857$ cro62 is from these laboratories. 
Table 5. Bacterial strains used in this study.

\begin{tabular}{|c|c|c|c|}
\hline Strain & $\begin{array}{l}\text { Parent } \\
\text { strain }\end{array}$ & Relevant genotype & Source \\
\hline AB1133 & & $\begin{array}{l}\text { thr1 leu6 thi1 supE44 lacY1 } \\
\text { galK2 ara14 xyl5 mtl1 } \\
\text { proA2 his4 argE3 str31 } \\
\text { sipA1 }\end{array}$ & L. S. Baron \\
\hline K37 & & galK, $\mathrm{Str}^{\mathrm{R}}$ & This laboratory \\
\hline K450 & K37 & nusB5 & This laboratory \\
\hline K556 & K37 & nusE71 & This laboratory \\
\hline K1947 & N5261 & $\begin{array}{l}\text { gal490* (chl-blu })_{d e l 8} \text { Bam }_{d e l} \\
N^{+} \text {cl14 H1 } 1_{d e l}\end{array}$ & M. Gottesman \\
\hline K1953 & K1947 & $\begin{array}{c}\text { gal490* }(\text { chl-blu })_{d e l 8} \text { Bam }_{\text {del }} \\
N^{+} \text {cl14 H1 } 1_{\text {del }} \text { nusE71 } \\
\text { zhb-3082::Tn } 10\end{array}$ & This work \\
\hline K2090 & K1953 & $\begin{array}{l}\text { gal490* }(\text { chl-blu })_{\text {dels }} \text { Bam }_{\text {del }} \\
N^{+} \text {cl14 H1 del } \text { nusE } 71 \\
\text { rpoAD305E } \\
\text { zhb-3082::Tn } 10\end{array}$ & This work \\
\hline K4069 & K37 & rpoAD305E & This work \\
\hline K6325 & K2090 & $\begin{array}{l}\text { gal490* (chl-blu })_{\text {del } 8} \text { Bam }_{\text {del }} \\
N^{+} \text {cl14 H1 } 1_{\text {del }} \text { nusE } 71 \\
\text { rpoAD305E } \\
\text { zhb-3082::Tn 10kan }\end{array}$ & This work \\
\hline K6953 & AB1133 & nusA1 rpoAD305E & This work \\
\hline K6995 & K6953 & $\mathrm{K} 6953+\mathrm{pNO} 2530$ & This work \\
\hline K7004 & K6953 & $\mathrm{K} 6953+\mathrm{pNO} 2530 *$ & This work \\
\hline K7005 & K1953 & K1953 + pNO2530* & This work \\
\hline K7006 & K1953 & $\mathrm{K} 1953+\mathrm{pNO} 2530$ & This work \\
\hline K4047 & K4069 & nusA1 rpoAD305E & This work \\
\hline K4090 & K4069 & nusB5 rpoAD305E & This work \\
\hline K7257 & K37 & $\mathrm{K} 37+$ pKKrpoA & This work \\
\hline K7254 & K37 & $\mathrm{K} 37+\mathrm{pKKrpoA}^{*}$ & This work \\
\hline K7258 & K37 & $\mathrm{K} 37+\mathrm{pKKrpoA} \Delta 3^{\prime}$ & This work \\
\hline K4195 & AB1133 & $\begin{array}{l}\text { nusA1 rpoAD305E nusE71 } \\
\text { zhb-3082::Tn } 10\end{array}$ & This work \\
\hline K8248 & K37 & $\begin{array}{l}\text { nusE } 71 \text { rpoAD305E } \\
\text { zhb-3082::Tn } 10\end{array}$ & This work \\
\hline NC221 & & $\begin{array}{l}\text { lacZu169 del gal490*(chl- } \\
\text { blu })_{\text {dels }} \text { Bam del N-lacZ } \\
\text { cl857 (cro-bioA) del } \\
\text { zhb-3082::Tn10 }\end{array}$ & This work \\
\hline NC222 & & 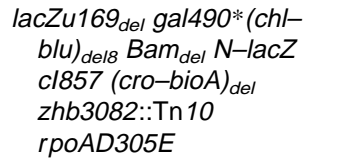 & This work \\
\hline
\end{tabular}

$\operatorname{Str}^{R}$, streptomycin resistant.

\section{Phage techniques}

Efficiency of phage plating (EOP) was determined as described previously (Friedman et al., 1984b). Dilution spot tests used to obtain a semi-quantitative evaluation of phage growth were performed by spotting drops of serial dilutions of phage on lawns formed from the indicated bacterium and scoring growth according to the dilutions that showed phage growth.

\section{Nucleic acid and protein procedures}

DNA preparation, restriction enzyme digestions, ligations, and transformations were performed essentially as described by Sambrook et al. (1989). Protein purification and twodimensional electrophoresis of ribosomal proteins have previously been described (Friedman et al., 1981). Western analysis was performed as previously described (Craven et al., 1994).

\section{DNA sequencing}

Sequenase version 2.0 dideoxy sequencing system (United States Biochemical) was employed using an $\left[\alpha^{-}{ }^{35}\right.$ S]-dATP (Amersham) label. Derivatives of M13mp18 or M13mp19 (Yanisch-Perron et al., 1985) carrying the desired cloned fragments served as single-stranded DNA templates for sequencing. The sequencing reactions were run on a six or eight percent polyacrylamide gel for varying lengths of time. Both strands of the DNA were sequenced.

\section{Galactokinase assay}

Enzyme levels were measured according to the published method (Adhya and Miller, 1979).

\section{Beta-galactosidase assay}

Enzyme levels were measured according to Miller (1992).

\section{Genetic techniques}

P1 transduction and Hfr crosses were performed in the standard manner (Miller, 1972; Sternberg and Maurer, 1991).

\section{Selection for second-site suppressors of nusE71}

This scheme, devised by Ward et al. (1983), uses derivatives of an E. coli K-12 strain, K1947, that has a fusion of the bacterial $g a /$ operon to the $\mathrm{pL}$ promoter of a defective $\lambda$ prophage. The abbreviated prophage also has the associated nutL signal, $N$ gene, and a defective $\mathrm{Cl}$ allele (Fig. 2). Additionally, there are at least two transcription-termination signals located between $\mathrm{pL}-$ nut and the gal operon. One of the terminators is located in an IS2 positioned in the leader region of the gal operon. This Rho-dependent terminator is very efficient and, therefore, in this construct, transcription initiating at pgal should terminate upstream of the gal genes. However, the prophage in $\mathrm{K} 1947$ does not express an active repressor and constitutively expresses $\mathrm{N}$ from the $\mathrm{pL}$ promoter. The expressed $\mathrm{N}$, in turn, modifies the RNA polymerase transcribing the $\mathrm{pL}$ operon, allowing transcription to transcend all downstream terminators and read into the galoperon, producing a Gal ${ }^{+}$phenotype.

In our adaptation of the selection, a derivative of K1947, $\mathrm{K} 1953$, carries the nusE71 mutation, causing $\mathrm{N}$ to be ineffective. Hence, the bacterium is $\mathrm{Gal}^{-}$even though $\mathrm{N}$ expression is constitutive. Suppressors of the $\mathrm{Nus}^{-}$phenotype should result in the bacteria being $\mathrm{Gal}^{+}$because $\mathrm{N}$ action would be supported. Gal ${ }^{+}$colonies were obtained (at a frequency of $\sim 10^{-8}$ ) and $\sim 80 \%$ of these supported $\lambda$ growth and, therefore, supported $\mathrm{N}$ action more effectively than did the starting parental recipient. We attempted to limit the mutant search to the 72 min region of the $E$. coli chromosome which has a large number of genes encoding ribosomal proteins (Nomura et al., 1977). Localized mutagenesis (Hong and Ames, 
1971) was employed using hydroxylamine treatment of a P1 lysate grown on a nusE71 host, K2016. This bacterium has a Tn 10 insertion (Kleckner et al., 1991) (zhb-3082::Tn 10, conferring resistance to tetracycline $\left(\right.$ Tet $\left.^{R}\right)$ ) linked to the $72 \mathrm{~min}$ region (Singer et al., 1989). Because P1 transducing particles can package $100 \mathrm{~kb}(2 \%)$ of the E. coli chromosome (Sternberg and Maurer, 1991), it was expected that by using this lysate to transduce for $\operatorname{Tet}^{\mathrm{R}}$, we would enrich for mutations in the $72 \mathrm{~min}$ region. Second-site suppressors were distinguished from true revertants using two-dimensional gel electrophoresis to determine if the $\mathrm{S} 10$ protein maintained the altered mobility caused by the nusE71 mutation (Friedman et al., 1981). One mutant, K2090, identified as having a second-site suppressor, was chosen for further characterization. The second-site mutation, rpoAD305E, was located to the $72 \mathrm{~min}$ region of the $E$. coligenetic map by cotransduction with zhb-3082::Tn 10. As the predominant change caused by hydroxylamine mutagenesis is C to T (Budowsky, 1976), we assume that the rpoAD305E mutation did not result from the hydroxylamine treatment but, instead, from a spontaneous mutation. The selection of an apparent spontaneous mutation following in vitro hydroxylamine mutagenesis of phage is not without precedent (Min Jou et al., 1972).

\section{Marker rescue of rpoAD305E}

K6325 (a derivative of K2090 with a substitution of a $k a n^{r}$ marker for the tet ${ }^{r}$ marker of zhb-3082::Tn 10) carrying pNO2530 was employed to transfer the rpoAD305E mutation to the plasmid by recombination between the chromosome and the cloned genes of the plasmid. Colonies containing such candidate recombinant plasmids were identified on MacConkey-galactose plates that contained ampicillin $\left(30 \mu \mathrm{g} \mathrm{ml}^{-1}\right)$ to maintain selective pressure for the plasmids. The starting strain has the $r p o A^{+}$allele on the plasmid and the rpoAD305E mutation on the chromosome. Because of partial dominance of $r p o A D 305 E$, K6325 with pNO2530 forms pink colonies on these indicator plates, unlike K6325, which forms dark-red colonies. However, dark-red colonies were occasionally observed $(\sim 1 / 100)$ when K6325 harbouring pNO2530 was plated on MacConkey-galactose-ampicillin plates. When these colonies were restreaked on the indicator plates containing ampicillin, dark-red colonies could be isolated. These bacteria obviously expressed higher levels of gal enzymes than those forming the pink colonies. We assumed that the rpoAD305E allele had recombined from the chromosome to the plasmid and the bacteria had become homogenotized for the mutant allele.

Plasmid DNA was isolated from a dark-red colony and this plasmid, named pNO2530*, was shown to have an insert that was seemingly identical to pNO2530. However, unlike pNO2530, pNO2530* suppressed the Nus ${ }^{-}$phenotype; when pNO2530* was transformed into the nusE71 parent strain, K1953, dark-red colonies were formed on MacConkey-galactose plates. The suppressor activity of pNO2530* was also assessed by phage plating. At $40^{\circ} \mathrm{C}, \lambda$ will not form plaques on a lawn of $\mathrm{K} 1953$, because $\mathrm{N}$-mediated antitermination is inoperative. $\lambda$ also fails to form plaques on a lawn of a derivative of K1953 carrying pNO2530, but does form plaques on a lawn of a derivative of K1953 carrying pNO2530* (data not shown). These results lead us to conclude that the rpoAD305E mutation had recombined from the chromosome to the plasmid, and that pNO2530* carries the rpoAD305E mutation.

\section{Crossing rpoAD305E away from nusE71}

A triple nusA1 nusE71 rpoAD305E mutant is thermosensitive, growing only at temperatures below $42^{\circ} \mathrm{C}$. Previous studies had shown that a nusA1 nusE71 double mutant grows at $42^{\circ} \mathrm{C}$ but fails to support growth of $\mathrm{N}$-dependent $\lambda$ phage (Friedman et al., 1983). Thus, if the rpoAD305E mutation suppresses the Nus ${ }^{-}$phenotype imposed by the nusA1 mutation, we suspected that it would be possible to select and screen for a nusA 1 rpoAD305E double mutant following $\mathrm{P} 1$ transduction from the nusE71 rpoAD305E zhb-3082::Tn10 donor to a nusA1 recipient. This could be accomplished by selecting for Tet $^{R}$ colonies at $42^{\circ} \mathrm{C}$ and screening the survivors for their Nus phenotype. Because nusE71, rpoAD305E, and zhb-3082::Th 10 are linked, one expected class of recombinants, triple nusA1 nusE71 rpoAD305E mutants, should be selected against by growing at the high temperature. Surviving bacteria that do not have rpoAD305E, but carry nusA1 only, or nusA1 and nusE71, should not support $\lambda$ growth at $42^{\circ} \mathrm{C}$. We expected that the nusA1 rpoAD305E double mutant might grow and support $\lambda$ growth at $42^{\circ} \mathrm{C}$. Recombinant progeny of such a cross were obtained at $42^{\circ} \mathrm{C}$ and screened for support of $\lambda$ growth at $42^{\circ} \mathrm{C} ; 4 \%$ of the Tet ${ }^{R}$ bacteria had this phenotype. One such recombinant, K4047, was chosen for further study. Genetic outcrosses confirmed that this recombinant contains the nusA 1 and rpoAD305E mutations (data not shown).

A nus $^{+}$recombinant, $\mathrm{K} 4069$, that has the rpoAD305E mutation free of any nus mutations was constructed by $\mathrm{P} 1$ transduction using $\mathrm{K} 4047$, the nusA1 rpoAD305E strain, as the donor. The recipient was the $\mathrm{K} 37 \mathrm{nus}^{+}$strain and the selective marker was the zhb-3082::Tn10 located near rpoAD305E. We could not ascribe any phenotype to the rpoAD305E mutation per se; therefore, potential rpoAD305E and $z h b-3082:: \operatorname{Tn} 10$ recombinants were backcrossed to the nusA1 mutant, K95. Because the $\operatorname{Tn} 10$ is near rpoA, we assumed that if a donor harboured the rpoAD305E mutation then some of the $\operatorname{Tet}^{\mathrm{R}}$ recombinants generated in the backcross would also acquire the rpoAD305E mutation. When one Tet $^{\mathrm{R}} \mathrm{K} 37$ derivative, $\mathrm{K} 4069$, was the donor in the backcross to $\mathrm{K} 95,14 / 30 \mathrm{Tet}^{\mathrm{R}}$ transductants scored as having suppressors of the Nus ${ }^{-}$phenotype, demonstrating that the donor K4069 strain contains the rpoAD305E allele.

\section{Acknowledgements}

The authors thank Gail Christie for kindly supplying the set of isogenic strains with rpoA mutations, Costa Georgopoulos for the nusE71 derivative with $z h b-3082:: \operatorname{Tn} 10$ (originally obtained from James Wechsler), and Richard Burgess for anti- $\alpha$ antibody. Eric Six, Richard Jaskunas, and Masayasu Nomura are thanked for plasmids and phage. Special thanks to Asis Das for helpful discussions and trenchant editorial comments. Helen Wilson is thanked for editorial comments as well as for sequencing the chromosomal rpoAD305E allele, and Melody Neeley is thanked for unpublished results. Work performed at 
the University of Michigan was supported by Public Health Grant Al11459-10 and GCRG Grant M01-RR0042 for sequence analysis. This research was also sponsored, in part, by the National Cancer Institute, DHHS, under contract with $A B L$. The contents of this publication do not necessarily reflect the views or policies of the Department of Health and Human Services, nor does mention of trade names, commercial products, or organizations imply endorsement by the US Government.

\section{References}

Adhya, S., and Miller, W. (1979) Modulation of the two promoters of the galactose operon of Escherichia coli. Nature 279: 492-494.

Ayers, D.J., Sunshine, M.G., Six, E.W., and Christie, G.E. (1994) Mutations affecting two adjacent amino acid residues in the alpha subunit of RNA polymerase block transcriptional activation by the P2 Ogr protein. J Bacteriol 176: 7430-7438.

Barik, S., Ghosh, B., Whalen, W., Lazinski, D., and Das, A. (1987) An antitermination protein engages the elongating transcription apparatus at a promoter-proximal recognition site. Cell 50: 885-899.

Bedwell, D.M., and Nomura, M. (1986) Feedback regulation of RNA polymerase subunit synthesis after the conditional overproduction of RNA polymerase in Escherichia coli. Mol Gen Genet 204: 17-23.

Blatter, E.E., Ross, W., Tang, H., Gourse, R.L., and Ebright, R.H. (1994) Domain organization of RNA polymerase a subunit: C-terminal 85 amino acids constitute a domain capable of dimerization and DNA binding. Cell 78: 889896.

de Boer, H.A. (1984) A versatile plasmid system for the study of prokaryotic transcription signals in Escherichia coli. Gene 30: 251-255.

Brosius, J., and Holy, A. (1984) Regulation of ribosomal RNA promoters with a synthetic lac operator. Proc Natl Acad Sci USA 81: 6929-6933.

Budowsky, E.I. (1976) The mechanism of the mutagenic action of hydroxylamines. Prog Nucl Acids Res Mol Biol 16: 125-188.

Cerretti, D.P., Dean, D., Davis, G.R., Bedwell, D.M., and Nomura, M. (1983) The $s p c$ ribosomal protein operon of Escherichia coli: sequence and cotranscription of the ribosomal protein genes and a protein export gene. NuCl Acids Res 11: 2599-2616.

Chattopadhyay, S., Garcia-Mena, J., DeVito, J., Wolska, K., and Das, A. (1995) Bipartite function of a small RNA hairpin in transcription antitermination in bacteriophage lambda. Proc Natl Acad Sci USA 92: 4061-4065.

Cheng, S.C., Lynch, E.C., Leason, K.R., Court, D.L., Shapiro, B.A., and Friedman, D.I. (1991) Functional importance of sequence in the stem-loop of a transcription terminator. Science 254: 1205-1207.

Cheng, S.C., Court, D.L., and Friedman, D.I. (1995) Transcription termination signals in the nin region of bacteriophage lambda: Identification of Rho-dependent termination regions. Genetics 140: 875-887.

Court, D.L., Patterson, T.A., Baker, N., Costantino, N., Mao,
C., and Friedman, D.I. (1995) Structural and functional analysis of the transcription-translation proteins NusB and NusE. J Bacteriol 177: 2589-2591.

Craven, M.G., Granston, A.E., Schauer, A.T., Zheng, C., Gray, T.A., and Friedman, D.I. (1994) Escherichia coliSalmonella typhimurium hybrid nusA genes: Identification of a short motif required for action of the $\lambda \mathrm{N}$ transcription antitermination protein. $J$ Bacteriol 176: 1394-1404.

Das, A. (1992) How the phage lambda $\mathrm{N}$ gene product suppresses transcription termination: communication of RNA polymerase with regulatory proteins mediated by signals in nascent RNA. J Bacteriol 174: 6711-6716.

Das, A. (1993) Control of transcription termination by RNAbinding proteins. Annu Rev Biochem 63: 893-930.

Das, A., and Wolska, K. (1984) Transcription antitermination in vitro by lambda $\mathrm{N}$ gene product: requirement for a phage nut site and the products of host nusA, nusB, and nusE genes. Cell 38: 165-173.

DeVito, J., and Das, A. (1994) Control of transcription processivity in phage lambda: Nus factors strengthen the termination-resistant state of RNA polymerase induced by $\mathrm{N}$ antiterminator. Proc Natl Acad Sci USA 91: 8660-8664.

Doelling, J.H., and Franklin, N.C. (1989) Effects of all single base substitutions in the loop of boxB on antitermination of transcription by bacteriophage lambda's $\mathrm{N}$ protein. Nucl Acids Res 17: 5565-5577.

Downing, W.L., Sullivan, S.L., Gottesman, M.E., and Dennis, P.P. (1990) Sequence and transcriptional pattern of the essential Escherichia coli secE-nusG operon. J Bacteriol 172: 1621-1627.

Duan, D.R., Pause, A., Burgess, W.H., Aso, T., Chen, D.Y., Garrett, K.P., Conaway, R.C., Conaway, J.W., Linehan, W.M., and Klausner, R.D. (1995) Inhibition of transcription elongation by the VHL tumor suppressor protein. Science 269: 1402-1406.

Ebright, R.H., and Busby, S. (1995) The Escherichia coli RNA polymerase a subunit: structure and function. Curr Op Genet Devel 5: 197-203.

Franklin, N.C. (1985) 'N' transcription antitermination proteins of bacteriophages lambda, phi 21 and P22. J Mol Biol 181: 85-91.

Friedman, D.I. (1988) Regulation of phage gene expression by termination and antitermination of transcription. In The Bacteriophages 2. Calendar, R. (ed.). New York: Plenum Press, pp. 263-319.

Friedman, D.I. (1992) Interaction between bacteriophage lambda and its Escherichia coli host. Curr Op Genet Dev 2: 727-738.

Friedman, D.I., and Court, D.L. (1995) Transcription antitermination: The lambda paradigm updated. Mol Microbiol 18: 191-200.

Friedman, D.I., and Olson, E.R. (1983) Evidence that a nucleotide sequence, 'boxA', is involved in the action of the NusA protein. Cell 34: 143-149.

Friedman, D.I., Schauer, A.T., Baumann, M.R., Baron, L.S., and Adhya, S.L. (1981) Evidence that ribosomal protein S10 participates in control of transcription termination. Proc Natl Acad Sci USA 78: 1115-1118.

Friedman, D.I., Schauer, A.T., Mashni, E.J., Olson, E.R., and Baumann, M.F. (1983) Escherichia coli factors involved in the action of the $\lambda$ gene $N$ antitermination function. In 
Microbiology. Schlessinger, D. (ed.). Washington, DC: American Society for Microbiology, pp. 39-42.

Friedman, D.I., Olson, E.R., Georgopoulos, C., Tilly, K., Herskowitz, I., and Banuett, F. (1984a) Interactions of bacteriophage and host macromolecules in the growth of bacteriophage lambda. Microbiol Rev 48: 299-325.

Friedman, D.I., Plantefaber, L.C., Olson, E.J., Carver, D., O'Dea, M.H., and Gellert, M. (1984b) Mutations in the DNA gyrB gene that are temperature sensitive for lambda sitespecific recombination, $\mathrm{Mu}$ growth, and plasmid maintenance. J Bacteriol 157: 490-497.

Friedman, D.I., Olson, E.R., Johnson, L.L., Alessi, D., and Craven, M.G. (1990) Transcription-dependent competition for a host factor: the function and optimal sequence of the phage lambda boxA transcription antitermination signal. Genes Dev 4: 2210-2222.

Garrett, K.P., Tan, S., Bradsher, J.N., Lane, W.S., Conaway, J.W., and Conaway, R.C. (1994) Molecular cloning of an essential subunit of RNA polymerase II elongation factor SIII. Proc Natl Acad Sci USA 91: 5237-5241.

Giladi, H., Igarashi, K., Ishihama, A., and Oppenheim, A.B. (1992) Stimulation of the phage lambda pL promoter by integration host factor requires the carboxy terminus of the alpha-subunit of RNA polymerase. $J$ Mol Biol 227: 985990.

Greenblatt, J., Nodwell, J.R., and Mason, S.W. (1993) Transcriptional antitermination. Nature 364: 401-406.

Hasan, N., and Szybalski, W. (1986) Boundaries of the nutL antiterminator of coliphage lambda and effects of mutations in the spacer region between box $A$ and boxB. Gene 50: 87-96.

Hayward, R.S., Igarashi, K., and Ishihama, A. (1991) Functional specialization within the alpha-subunit of Escherichia coli RNA polymerase. J Mol Biol 221: 23-29.

Hong, J.S., and Ames, B.N. (1971) Localized mutagenesis of any specific small region of the bacterial chromosome. Proc Natl Acad Sci USA 68: 3158-3162.

Horwitz, R.J., Li, J., and Greenblatt, J. (1987) An elongation control particle containing the $\mathrm{N}$ gene transcriptional antitermination protein of bacteriophage lambda. Cell 51: 631-641.

Ishihama, A. (1992) Role of the RNA polymerase alpha subunit in transcription activation. Mol Microbiol 6: 3283-3288.

Jin, D.J., Cashel, M., Friedman, D.I., Nakamura, Y., Walter, W.A., and Gross, C.A. (1988) Effects of rifampicin resistant $r p o B$ mutations on antitermination and interaction with nusA in Escherichia coli. J Mol Biol 204: 247-261.

Kleckner, N., Bender, J., and Gottesman, S. (1991) Uses of transposons with emphasis on Tn 10. Meth Enzymol 204: 139-180.

Kur, J., Hasan, N., and Szybalski, W. (1989) Repression of transcription from the b2-att region of coliphage lambda by integration host factor. Virology 168: 236-244.

Kuroki, K., Ishii, S., Kano, Y., Miyashita, T., Nishi, K., and Imamoto, F. (1982) Involvement of the nusB gene products in transcription of Escherichia coli tryptophan operon in vitro. Mol Gen Genet 185: 369-371.

Latif, F., Tory, K., Gnarra, J., Yao, M., Duh, F.M., Orcutt, M.L., Stackhouse, T., Kuzmin, I., Modi, W., and Geil, L. (1993) Identification of the von Hippel-Lindau disease tumor suppressor gene. Science 260: 1317-1320.
Lazinski, D., Grzadzielska, E., and Das, A. (1989) Sequencespecific recognition of RNA hairpins by bacteriophage antiterminators requires a conserved arginine-rich motif. Cell 59: 207-218.

Li, J., Horwitz, R., McCracken, S., and Greenblatt, J. (1992) NusG, a new Escherichia coli elongation factor involved in transcriptional antitermination by the $\mathrm{N}$ protein of phage lambda. J Biol Chem 267: 6012-6019.

Liu, K., and Hanna, M.M. (1995) NusA interferes with interactions between the nascent RNA and the C-terminal domain of the alpha subunit of RNA polymerase in Escherichia coli transcription complexes. Proc Natl Acad Sci USA 92: 5012-5016.

Liu, K., Zhang, Y., Severinov, K., Das, A., and Hannah, M.M. (1996) Role of Escherichia coli RNA polymerase alpha subunit in modulation of pausing, termination and antitermination by the transcription elongation factor NusA. EMBO J 15: 150-161.

Lombardo, M.J., Bagga, D., and Miller, C.G. (1991) Mutations in rpoA affect expression of anaerobically regulated genes in Salmonella typhimurium. J Bacteriol 173: 7511-7518.

McKenney, K., Shimatake, H., Court, D., Schmeissner, U., Brady, C., and Rosenberg, M. (1981) A system to study promoter and terminator signals recognized by Escherichia coli RNA polymerase. Gene Amplif Anal 2: 383-415.

Meek, D.W., and Hayward, R.S. (1984) Nucleotide sequence of the rpoA-rp/Q DNA of Escherichia coli: a second regulatory binding site for protein S5? Nucl Acids Res 12: 13-21.

Miller, J.H. (1972) Experiments in Molecular Genetics. Cold Spring Harbor, New York: Cold Spring Harbor Laboratory Press.

Miller, J.H. (1992) A Short Course in Bacterial Genetics. A Laboratory Manual for Escherichia coli and Related Bacteria. Cold Spring Harbor, New York: Cold Spring Harbor Laboratory Press.

Miller, H.I., and Friedman, D.I. (1980) An E. coli gene product required for lambda site-specific recombination. Cell 20: 711-719.

Min Jou, W., Haegeman, G., Ysebaert, M., and Fiers, W. (1972) Nucleotide sequence of the gene coding for the bacteriophage MS2 coat protein. Nature 237: 82-88.

Miyashita, T., Kano, Y., Kuroki, K., Ishii, S., and Imamoto, F. (1982) In vivo evidence for nusA and nusB gene function in general transcription of the Escherichia coli genome. Biken J 25: 121-130.

Mogridge, J., Mah, T.-F., and Greenblatt, J. (1995) A protein-RNA interaction network facilitates the templateindependent cooperative assembly on RNA polymerase of a stable antitermination complex containing the I $\mathrm{N}$ protein. Genes Dev 9: 2831-2844.

Nodwell, J.R., and Greenblatt, J. (1991) The nut site of bacteriophage lambda is made of RNA and is bound by transcription antitermination factors on the surface of RNA polymerase. Genes Dev 5: 2141-2151.

Nodwell, J.R., and Greenblatt, J. (1993) Recognition of boxA antiterminator RNA by the $E$. coli antitermination factors NusB and ribosomal protein S10. Cell 72: 261-268.

Nomura, M., Morgan, E.A., and Jaskunas, S.R. (1977) Genetics of bacterial ribosomes. Annu Rev Genet 11: 297-347. 
Olson, E.R., Flamm, E.L., and Friedman, D.I. (1982) Analysis of nutR: a region of phage lambda required for antitermination of transcription. Cell 31: 61-70.

Olson, E.R., Tomich, C.S., and Friedman, D.I. (1984) The $n u s A$ recognition site. Alteration in its sequence or position relative to upstream translation interferes with the action of the $\mathrm{N}$ antitermination function of phage lambda. $\mathrm{J} \mathrm{Mol} \mathrm{Biol}$ 180: 1053-1063.

Patterson, T.A., Zhang, Z., Baker, T., Johnson, L.L., Friedman, D.I., and Court, D.L. (1994) Bacteriophage lambda $\mathrm{N}$-dependent transcription antitermination. Competition for an RNA site may regulate antitermination. $J$ Mol Biol 236: 217-228.

Roberts, J. (1992) Antitermination and the control of transcription elongation. In Transcriptional Regulation. S.L. McKnight, and K.R. Yamamoto (eds). Cold Spring Harbor, New York: Cold Spring Harbor Laboratory Press, pp. 389-406.

Roberts, J.W. (1969) Termination factor for RNA synthesis. Nature 224: 1168-1174.

Roberts, J.W. (1993) RNA and protein elements of E. coli and lambda transcription antitermination complexes. Cell 72: 653-655.

Rosenberg, M., Court, D., Shimatake, H., Brady, C., and Wulff, D.L. (1978) The relationship between function and DNA sequence in an intercistronic regulatory region in phage lambda. Nature 272: 414-423.

Ross, W., Gosink, K.K., Salomon, J., Igarashi, K., Zou, C., Ishihama, A., Severinov, K., and Gourse, R.L. (1993) A third recognition element in bacterial promoters: DNA binding by the alpha subunit of RNA polymerase. Science 262: 1407-1413.

Russo, F.D., and Silhavy, T.J. (1992) Alpha: the Cinderella subunit of RNA polymerase. J Biol Chem 267: 14515-14518.

Salstrom, J.S., and Szybalski, W. (1978a) Coliphage lambda nutL: a unique class of mutants defective in the site of gene $\mathrm{N}$ product utilization for antitermination of leftward transcription. J Mol Biol 124: 195-221.

Salstrom, J.S., and Szybalski, W. (1978b) Transcription termination sites in the major leftward operon of coliphage lambda. Virology 88: 252-262.

Sambrook, J., Fritsch, E., and Maniatis, T. (1989) Molecular Cloning: A Laboratory Manual. Cold Spring Harbor, New York: Cold Spring Harbor Laboratory Press.

Schauer, A.T. (1985) Proteins involved in phage lambda transcription antitermination. PhD thesis. University of Michigan, Ann Arbor, Michigan, USA.

Schauer, A.T., and Friedman, D.I. (1985) Gene expression in coliphage $\lambda$ : Proteins and sites involved in transcription antitermination. In Sequence Specificity in Transcription and Translation. Calendar, R., and Gold, L. (eds). New York: Alan R. Liss Inc., pp. 171-184.

Schauer, A.T., Carver, D.L., Bigelow, B., Baron, L.S., and Friedman, D.I. (1987) Lambda N antitermination system: functional analysis of phage interactions with the host NusA protein. J Mol Biol 194: 679-690.

Singer, M., Baker, T.A., Schnitzler, G., Deischel, S.M., Goel, M., Dove, W., Jaacks, K.J., Grossman, A.D., Erickson, J.W., and Gross, C.A. (1989) A collection of strains containing genetically linked alternating antibiotic resistance elements for genetic mapping of Escherichia coli. Microbiol Rev 53: 1-24.
Slauch, J.M., Russo, F.D., and Silhavy, T.J. (1991) Suppressor mutations in rpoA suggest that $\mathrm{OmpR}$ controls transcription by direct interaction with the alpha subunit of RNA polymerase. J Bacteriol 173: 7501-7510.

Somasekhar, G., Drahos, D., Salstrom, J.S., and Szybalski, W. (1982) Sequence changes in coliphage lambda mutants affecting the nutL antitermination site and termination by tL1 and tL2. Gene 20: 477-480.

Sparkowski, J., and Das, A. (1992) Simultaneous gain and loss of functions caused by a single amino acid substitution in the beta subunit of Escherichia coli RNA polymerase: suppression of nusA and rho mutations and conditional lethality. Genetics 130: 411-428.

Sternberg, N.L., and Maurer, R. (1991) Bacteriophagemediated generalized transduction in Escherichia coli and Salmonella typhimurium. Meth Enzymol 204: 18-43.

Sullivan, S.L., and Gottesman, M.E. (1992) Requirement for E. coli NusG protein in factor-dependent transcription termination. Cell 68: 989-994.

Sullivan, S.L., Ward, D.F., and Gottesman, M.E. (1992) Effect of Escherichia coli nusG function on lambda Nmediated transcription antitermination. $J$ Bacteriol 174: 1339-1344.

Sunshine, M.G., and Sauer, B. (1975) A bacterial mutation blocking P2 phage late gene expression. Proc Natl Acad Sci USA 72: 2770-2774.

Tsugawa, A., Saito, M., Court, D.L., and Nakamura, Y. (1988) nusA amber mutation that causes temperaturesensitive growth of Escherichia coli. J Bacteriol 170: 908915.

Ward, D.F., and Gottesman, M.E. (1981) The nus mutations affect transcription termination in Escherichia coli. Nature 292: 212-215.

Ward, D.F., DeLong, A., and Gottesman, M.E. (1983) Escherichia coli nusB mutations that suppress nusA1 exhibit lambda N specificity. J Mol Biol 168: 73-85.

Warren, F., and Das, A. (1984) Formation of terminationresistant transcription complex at phage lambda nut locus: effects of altered translation and a ribosomal mutation. Proc Natl Acad Sci USA 81: 3612-3616.

Yager, T.D., and von Hippel, P.H. (1987) Transcript elongation and termination in Escherichia coli. In Escherichia coli and Salmonella typhimurium: Cellular and Molecular Biology. F.C. Neidhardt et al. (eds). Washington, DC: ASM, pp. 1241-1275.

Yanisch-Perron, C., Vieira, J., and Messing, J. (1985) Improved M13 phage cloning vectors and host strains: nucleotide sequences of the M13mp18 and pUC19 vectors. Gene 33: 103-119.

Zheng, C., and Friedman, D.I. (1994) Reduced Rhodependent transcription termination permits NusA-independent growth of Escherichia coli. Proc Natl Acad Sci USA 91: 7543-7547.

Zou, C., Fujita, N., Igarashi, K., and Ishihama, A. (1992) Mapping the CAMP receptor protein contact site on the alpha subunit of Escherichia coli RNA polymerase. $\mathrm{Mol}$ Microbiol 6: 2599-2605.

Zuber, M., Patterson, T.A., and Court, D.L. (1987) Analysis of nutR, a site required for transcription antitermination in phage lambda. Proc Natl Acad Sci USA 84: 45144518. 